\title{
A Method for Improving Out-Of-Band Characteristics of a Wideband Bandpass Filter in an LTCC Substrate
}

\author{
Shinpei Oshima, Koji Wada1, Ryuji Murata and Yukihiro Shimakata \\ TAIYO YUDEN CO., LTD \\ ${ }^{1}$ The University of Electro-communications \\ Japan
}

\section{Introduction}

Recently, compact wireless modules using low temperature co-fired ceramic (LTCC) technology are widely used for the wireless systems such as mobile phones, Bluetooth, and wireless local-area networks(Lin et al.,2004; Wang et al.,2005). Fig.1 shows the general structure of the compact wireless modules using the LTCC technology. The modules consist of an LTCC substrate, integrated circuits, chip components, a shield, and passive components embedded in the LTCC substrate (e.g., the bandpass filter, coupler and balun). The embedded components in the LTCC substrate are fabricated by using the multilayer structures based on thin ceramic sheets and conductor patterns. It becomes possible to produce very compact modules compared to those with a general printed circuit board substrate, because a number of passive components can be embedded in the substrate. To adapt this technology for ultra wideband (UWB) wireless systems, a wideband bandpass filter in the LTCC substrate is one of the most important technology because it decreases the influences from other wireless systems. Various wideband bandpass filters have already been presented(Ishida \& Araki, 2004; Saitou et al.,2005; Li et al., 2005; Zhu et al.,2005; Horii

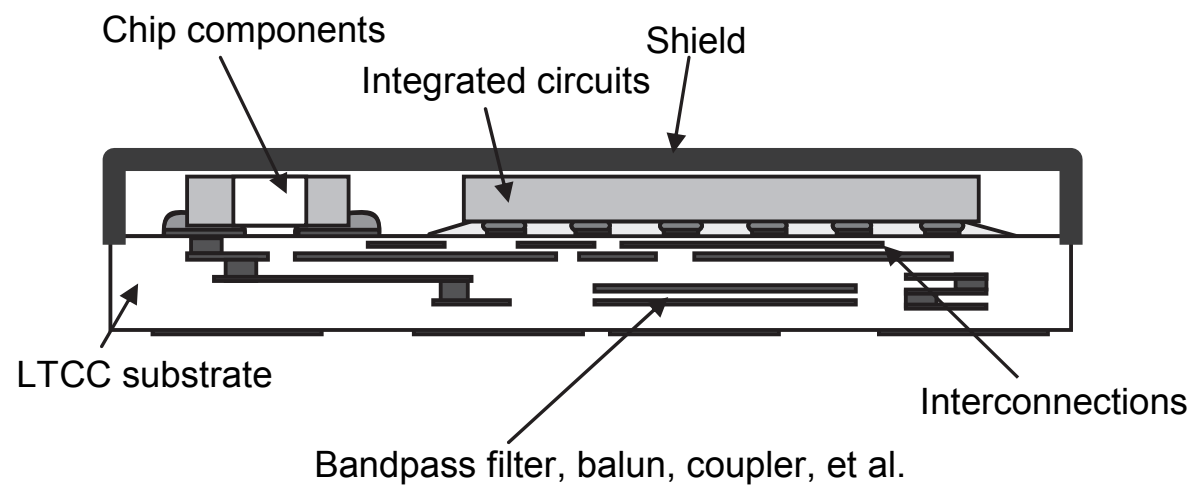

Fig. 1. A general structure of the compact wireless module using the LTCC technology. 
et al.,2006; Yamamoto et al.,2007; Shaman \& Hong,2007; Tanii et al., 2008 ; Sun \& Zhu, 2009). However, these approaches cannot be easily applied for the embedded components in the LTCC substrate. Therefore we have studied the compact wideband bandpass filters based on the LTCC technology(Oshima et al.,2008; Oshima et al.,2010).

In this study, we propose a method for improving out-of-band characteristics of a wideband bandpass filter. It is suitable for the compact UWB wireless modules using the LTCC technology. The UWB systems assume the band group $1(3.168-4.752 \mathrm{GHz})$ of the multiband orthogonal frequency-division multiplexing systems (Ghorashi et al., 2004).

Section 2 describes a wideband filter using the LTCC technology. We also point out that the filter is desired to improve the attenuation characteristics. Section 3 explains a method for improving out-of-band characteristics. In Section 4 and Section 5, we indicate the LTCC structure of the presented filter, the simulated results, and the experimental results. Finally, the conclusion of this study is summarized in Section 6.

\section{Bandpass filter for UWB systems using the low-frequency band}

Fig.2 shows the schematic of the wideband bandpass filter for UWB systems using the lowfrequency band (Oshima et al., 2010). Resonator 2 is the resonator which has a wide passband and creates attenuation poles near the passband. Resonator 1 and Resonator 3 are tap-feed resonators. The capacitors of $C_{2}$ and $C_{3}$ are coupling capacitors between the resonators. The capacitors of $\mathrm{C}_{4}$ and $\mathrm{C}_{5}$ are used for the impedance matching and they also improve out-of-band characteristics in the high-frequency region. The capacitor $\mathrm{C}_{6}$ is used to shorten the length of the strip line. In this study, the length of Resonator 3 differs from that of Resonator 1 in order to create two attenuation poles at the high-frequency region. The attenuation pole created by Resonator 1 is given by

$$
\frac{\mathrm{j} \mathrm{Z}_{\mathrm{A}} \mathrm{Z}_{\mathrm{B}}}{\mathrm{Z}_{\mathrm{A}} \cot \theta_{\mathrm{B}}-\mathrm{Z}_{\mathrm{B}} \tan \theta_{\mathrm{A}}}=0
$$

The attenuation pole created by Resonator 3 is also given by

$$
\frac{j Z_{\mathrm{E}} \mathrm{Z}_{\mathrm{F}}}{\mathrm{Z}_{\mathrm{E}} \cot \theta_{\mathrm{F}}-\mathrm{Z}_{\mathrm{F}} \tan \theta_{\mathrm{E}}}=0 .
$$

The attenuation poles created by Resonator 2 are given by

$$
\frac{\mathrm{Y}_{0}\left(\mathrm{Y}_{1}-\mathrm{Y}_{2}\right)}{\left(\mathrm{Y}_{0}+\mathrm{Y}_{1}\right)\left(\mathrm{Y}_{0}+\mathrm{Y}_{2}\right)}=0
$$

where,

$$
\begin{gathered}
Y_{0}=0.02 \\
Y_{1}=\frac{1-2 \omega C_{1} Z_{D} \tan \theta_{D}}{j Z_{D} \tan \theta_{D}} \\
Y_{2}=\frac{j \tan \theta_{D}+Y_{3} Z_{D}}{Z_{D}+j Y_{3} Z_{D}^{2} \tan \theta_{D}}
\end{gathered}
$$




$$
Y_{3}=\frac{j\left(\omega C_{6} Z_{C}+\tan \theta_{C}\right)}{2 Z_{C}\left(1-\omega C_{6} Z_{C} \tan \theta_{C}\right)}
$$

The circuit parameters of the bandpass filter are decided by means of adjusting the parameters in consideration of the conditions for the attenuation poles. This adjustment is carried out by a commercial circuit simulator (ADS, Agilent Technologies, Inc.). Table 1 shows the parameters of the filter. Here, the reference frequency for the electrical length is 4.0 GHz. In this study, we use the physical strip line model in the circuit simulation because this model can simulate the losses of the conductor and the LTCC substrate. Fig. 3 shows the physical strip line model. The relative permittivity of the LTCC substrate and the dielectric loss tangent of the substrate are 7.1 and 0.005 , respectively. The conductor in the substrate is silver. Fig.4 indicates the results of the circuit simulation. The filter produces good attenuation performances near the passband due to attenuation poles $\left(f_{1}\right.$ and $\left.f_{2}\right)$ which are created by Resonator 2 . The filter achieves good spurious suppression up to $10 \mathrm{GHz}$ due to the attenuation poles $\left(f_{3}\right.$ and $\left.f_{4}\right)$. They are created by Resonator 1 and Resonator 3 . The input impedance of the filter is also $50 \mathrm{ohm}$ in the wide passband. However this filter is desired to improve the attenuation characteristics because the filter cannot create a number of attenuation poles at the frequency region lower than the passband and has the spurious responses at the frequency band higher than $10 \mathrm{GHz}$.

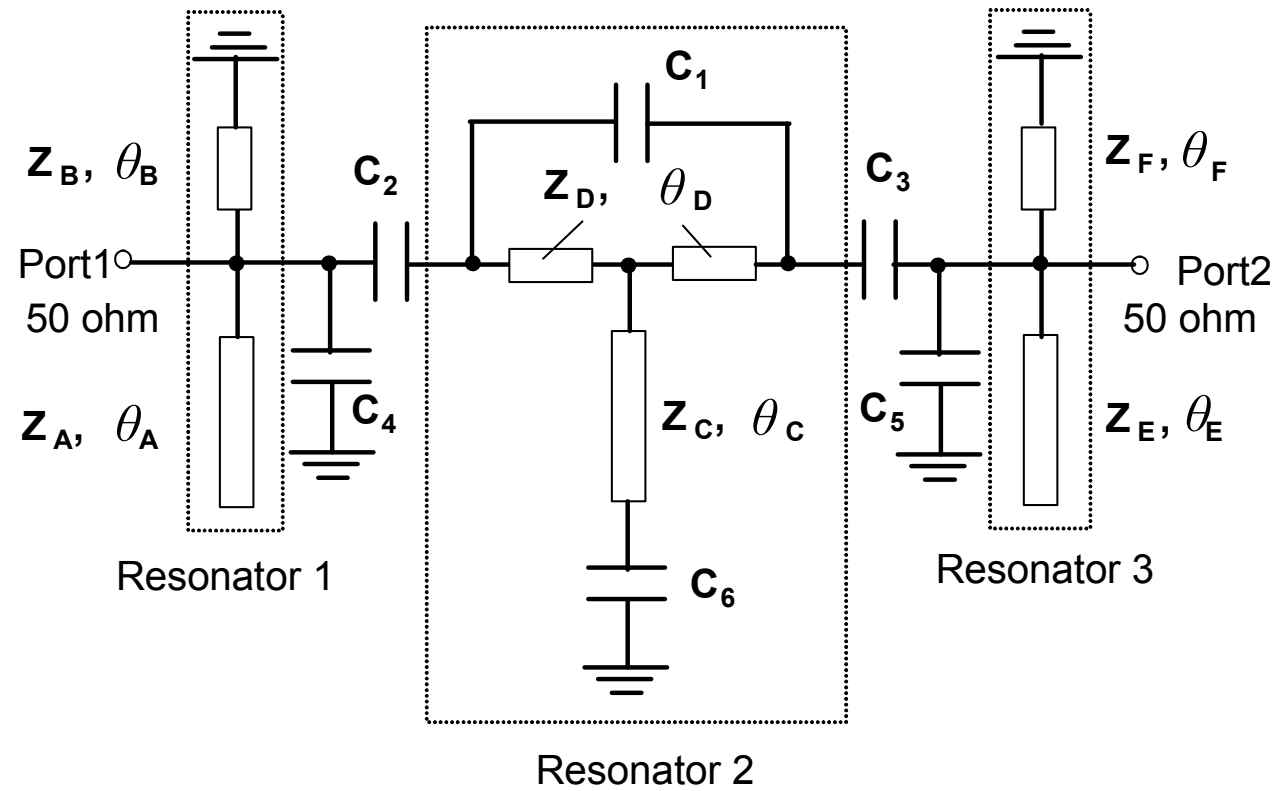

Fig. 2. Schematic of the UWB bandpass filter for the low-frequency band. 


\begin{tabular}{|c|c|c|c|c|c|}
\hline $\mathrm{C}_{1}$ & $1.0 \mathrm{pF}$ & $\mathrm{Z}_{\mathrm{A}}$ & $46.3 \mathrm{ohm}$ & $\theta_{A}$ & $43.9 \mathrm{deg}$. \\
\hline $\mathrm{C}_{2}$ & $0.75 \mathrm{pF}$ & $\mathrm{Z}_{\mathrm{B}}$ & $46.3 \mathrm{ohm}$ & $\theta_{B}$ & $26.9 \mathrm{deg}$. \\
\hline $\mathrm{C}_{3}$ & $0.75 \mathrm{pF}$ & $\mathrm{Z}_{\mathrm{C}}$ & $46.3 \mathrm{ohm}$ & $\theta_{C}$ & $50.9 \mathrm{deg}$. \\
\hline $\mathrm{C}_{4}$ & $0.5 \mathrm{pF}$ & $\mathrm{Z}_{\mathrm{D}}$ & $38.6 \mathrm{ohm}$ & $\theta_{D}$ & $15.7 \mathrm{deg}$. \\
\hline $\mathrm{C}_{5}$ & $0.5 \mathrm{pF}$ & $\mathrm{Z}_{\mathrm{E}}$ & $46.3 \mathrm{ohm}$ & $\theta_{E}$ & $38.4 \mathrm{deg}$. \\
\hline $\mathrm{C}_{6}$ & $2.7 \mathrm{pF}$ & $\mathrm{Z}_{\mathrm{F}}$ & $46.3 \mathrm{ohm}$ & $\theta_{F}$ & $26.9 \mathrm{deg}$. \\
\hline
\end{tabular}

Table 1. Parameters for the schematic shown in Fig.2.

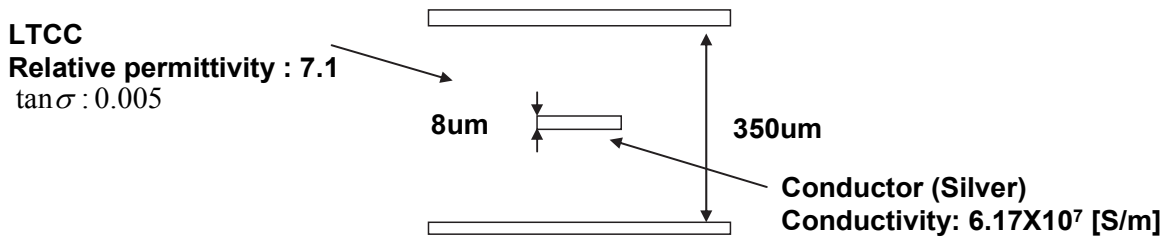

Fig. 3. Physical model for a stripline.

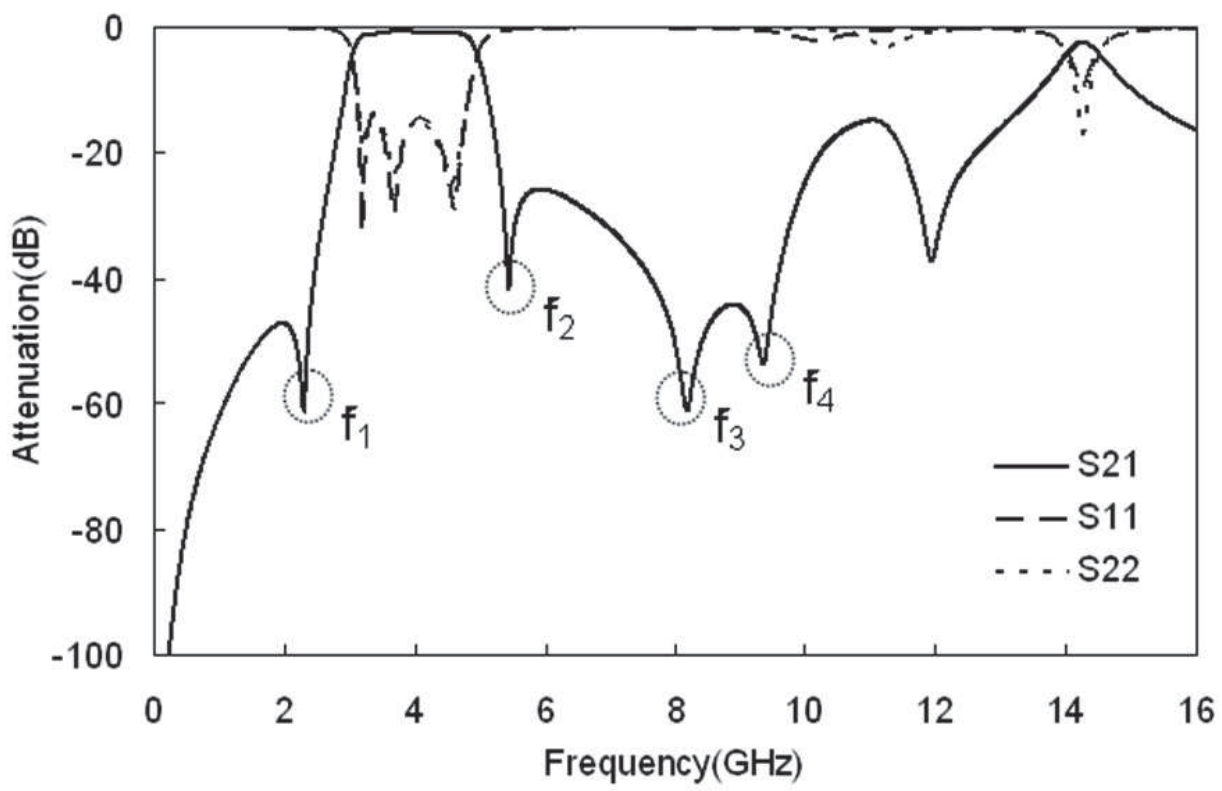

Fig. 4. Simulated results of the filter shown in Fig.2. 


\section{A method for improving out-of-band characteristics}

In order to improve the spurious responses, the lowpass filter is very useful (Kurita \& $\mathrm{Li}$, 2007.). Fig.5 shows the schematic of the lowpass filter. This filter consists of a stripline and a capacitor, which is suitable for the embedded components in the LTCC substrate (Ohwada et al., 2002.). Fig.6 indicates the simulated results of the lowpass filter by the circuit simulator. Where, $\mathrm{Z}_{\mathrm{S}}$ and $\theta_{\mathrm{S}}$ are $46.3 \mathrm{ohm}$ and $33 \mathrm{deg}$.(@4GHz), respectively. In Case $\mathrm{A}$, the capacitor $C_{a}$ is $0.27 \mathrm{pF}$. In Case $B$, the capacitor is $0.34 \mathrm{pF}$. This lowpass filter can attenuate the frequency region which is higher than $10 \mathrm{GHz}$. The attenuation characteristics of the filter can be controlled by the value of the capacitor $C_{a}$. However, the lowpass filter can not attenuate the low-frequency band.

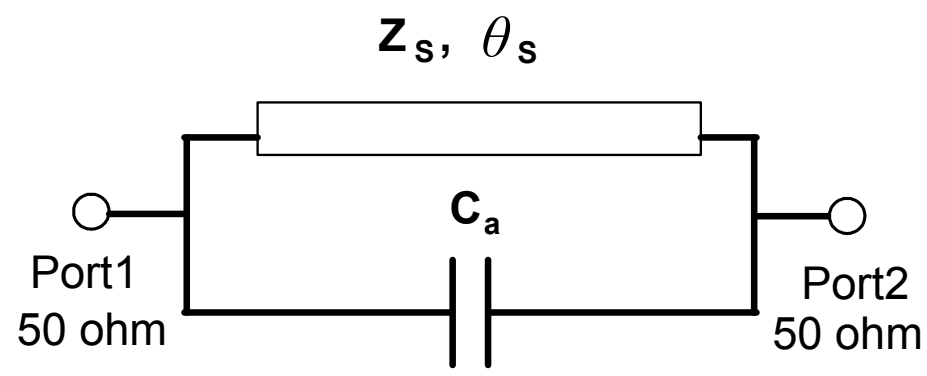

Fig. 5. Schematic of the lowpass filter.

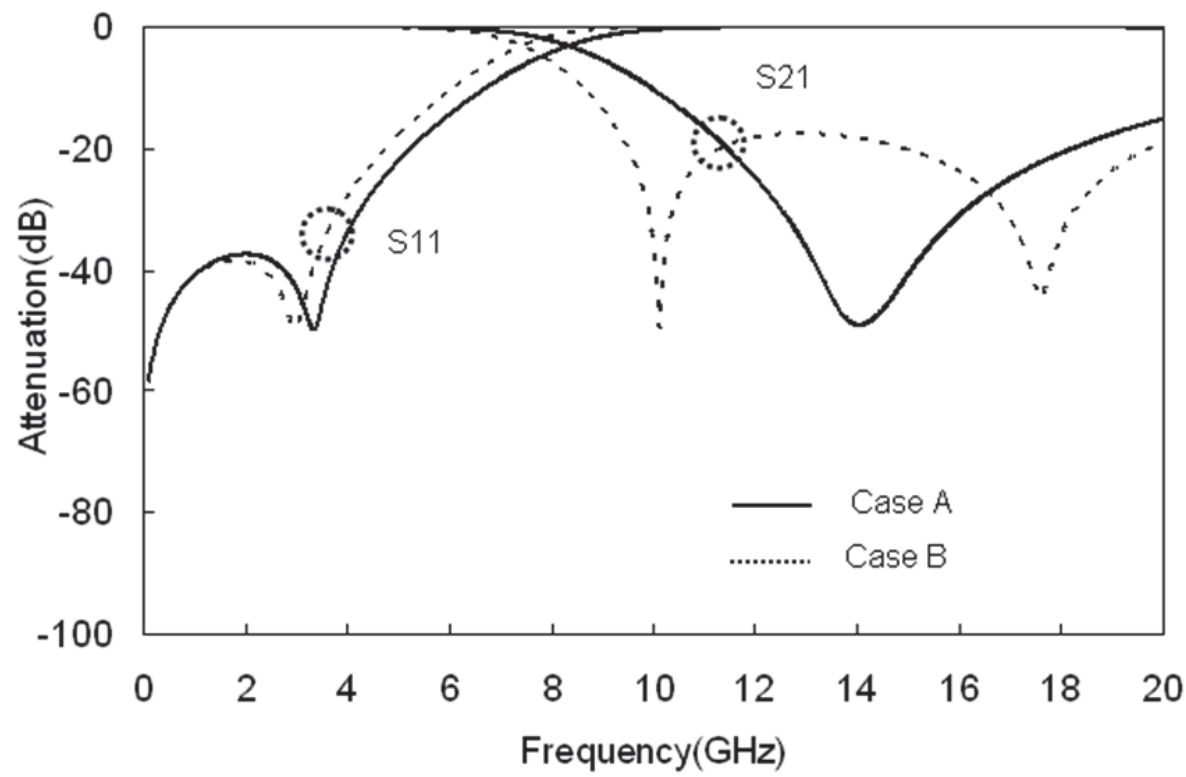

Fig. 6. Simulated results of the lowpass filter shown in Fig.5. 
The input/output coupled filter can create attenuation poles (Shaman \& Hong. 2007). It is useful for improving the attenuation performances near the passband. However this filter requires the quarter-wavelength coupled line and has the third harmonic.

For improving the out-of-band characteristics of the filter, we propose a method using lowpass filters which consist of the coupling structure. Fig.7 shows the schematic of the filter using the presented method. This circuit adds the lowpass filters at the input/output ports of the filter shown in Fig.2. And a part of the stripline of the lowpass filters is the coupling structure. Table 2 shows the parameters of the lowpass filters shown in Fig.7. In Table 2, the reference frequency for the electrical length is $4.0 \mathrm{GHz}$. $Z_{\text {So }}$ and $Z_{S e}$ are odd- and even-mode characteristic impedances. Fig.8 indicates the simulated results of the filter. We can confirm that the filter has an additional attenuation pole $\left(\mathrm{f}_{5}\right)$ at the low-frequency band and suppresses the second and third harmonics. Fig.9 shows the characteristics of the filter, when the coupling condition of the stripline is varied. It is confirmed that the attenuation pole $\left(f_{5}\right)$ is controlled by the coupling stripline. This method uses the weak coupling condition. Therefore it has little effect on the passband and the attenuation poles near the passband. The filter keeps a high attenuation level in the high-frequency region. Note that the locations of attenuation poles especially in the high-frequency region are varied by the coupling condition.

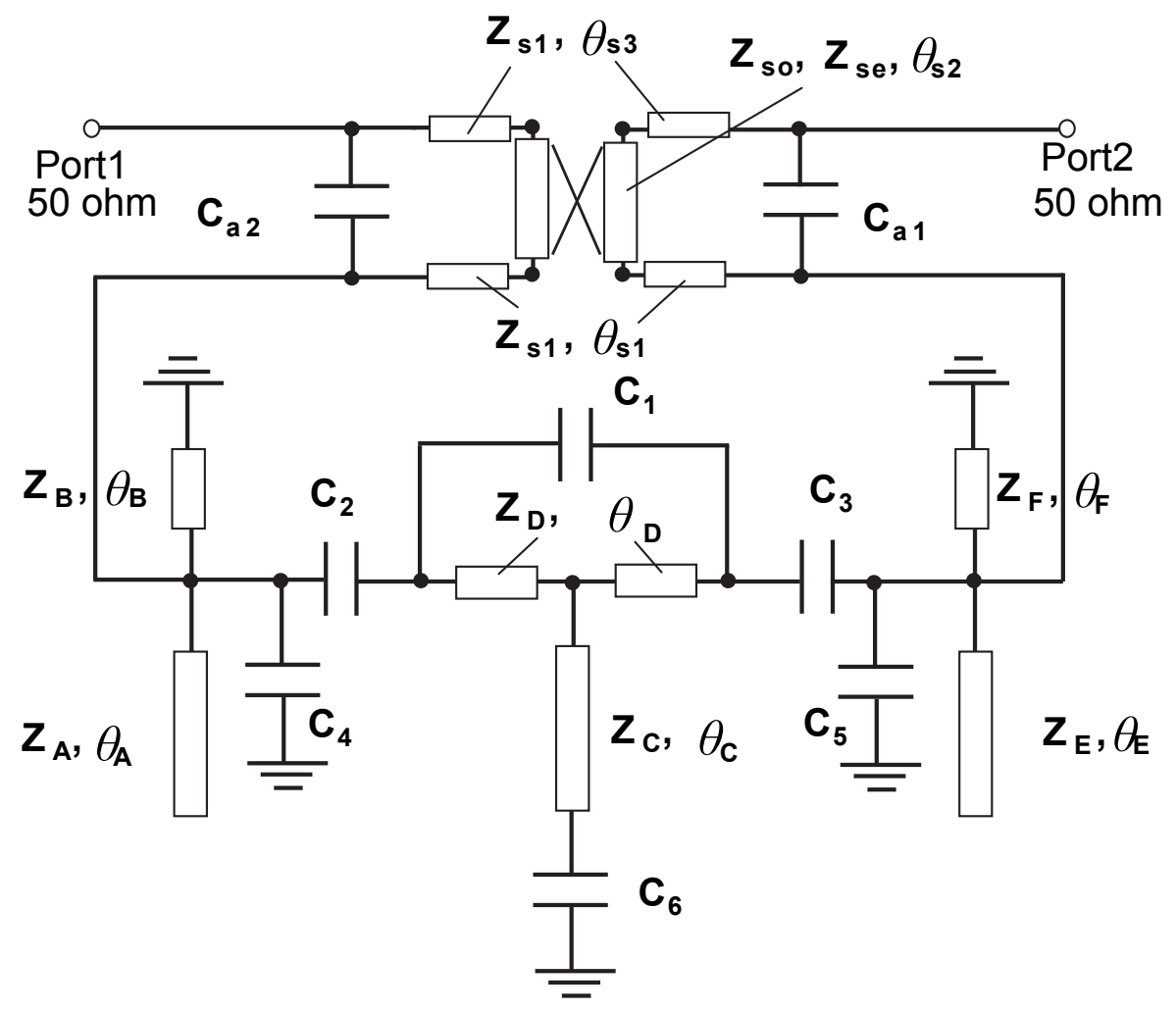

Fig. 7. Schematic of the bandpass filter. 


\begin{tabular}{|c|c|c|c|c|c|c|c|}
\hline $\mathrm{C}_{\mathrm{a} 1}$ & $0.27 \mathrm{pF}$ & $\mathrm{Z}_{\mathrm{S} 1}$ & $46.3 \mathrm{ohm}$ & $\mathrm{Z}_{\mathrm{So}}$ & $45.7 \mathrm{ohm}$ & $\theta_{S 2}$ & $10 \mathrm{deg}$. \\
\hline $\mathrm{C}_{\mathrm{a} 2}$ & $0.25 \mathrm{pF}$ & $\mathrm{Z}_{\mathrm{Se}}$ & $45.9 \mathrm{ohm}$ & $\theta_{S 1}$ & $18 \mathrm{deg}$. & $\theta_{S 3}$ & $5 \mathrm{deg}$. \\
\hline
\end{tabular}

Table 2. Parameters of the lowpass filters shown in Fig.7.

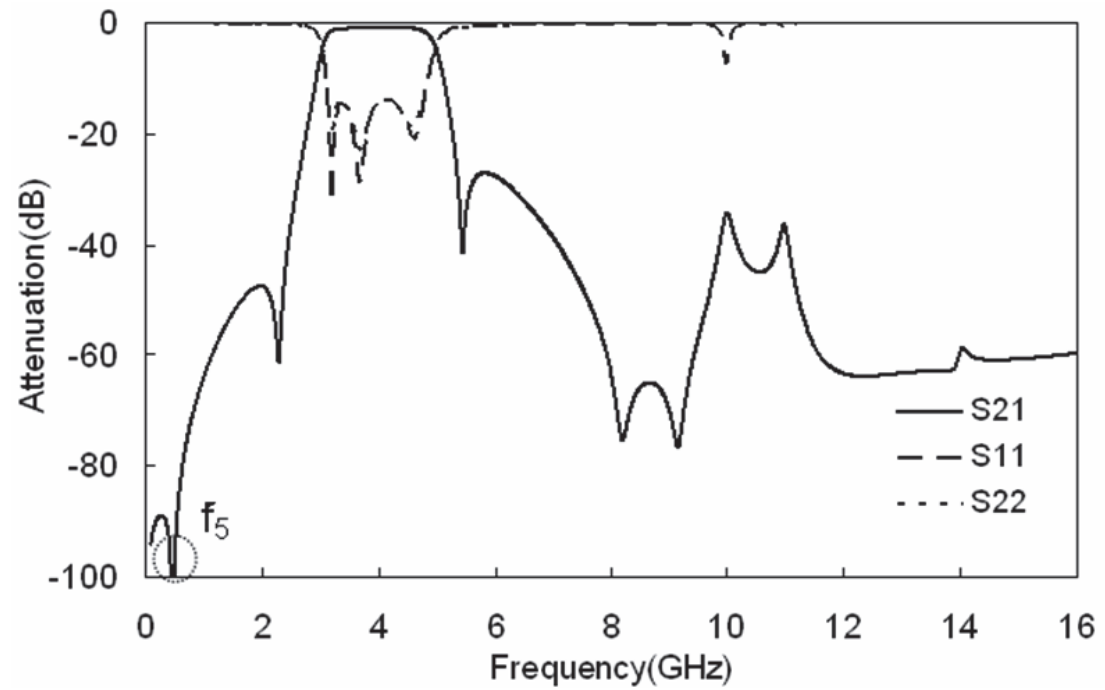

Fig. 8. Simulated results of the filter shown in Fig.7.

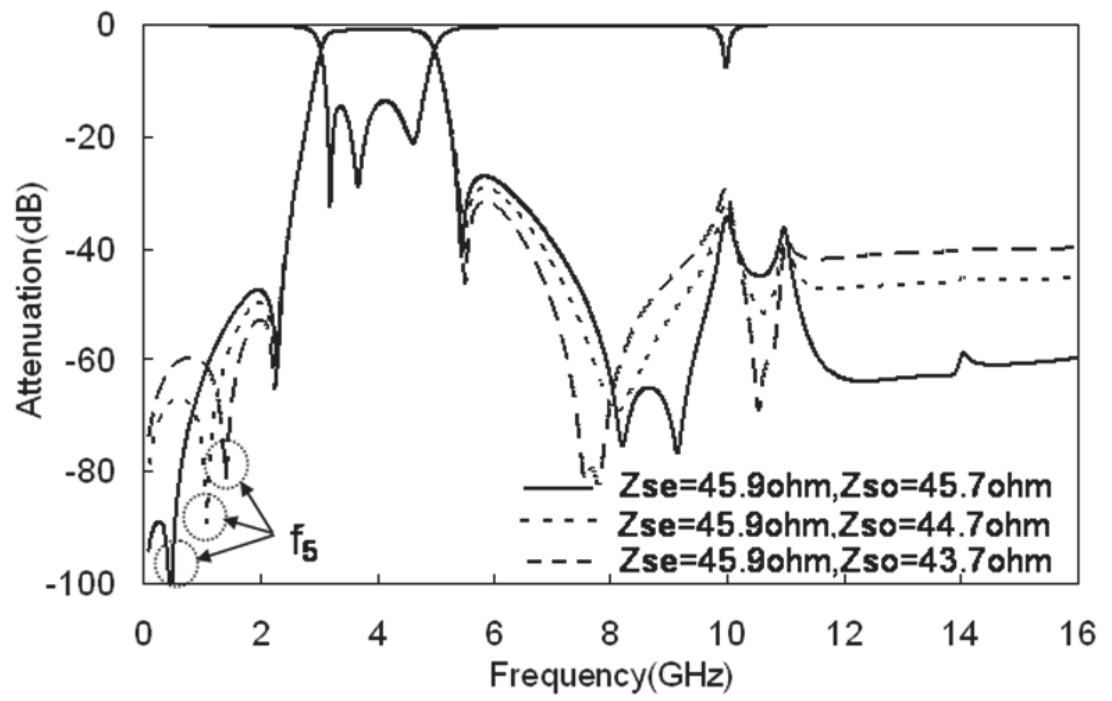

Fig. 9. Simulated results of the filter shown in Fig.7, when the coupling condition of the stripline is varied. 


\section{LTCC structure}

Fig.10, Fig.11 and Fig.12 indicate the LTCC structure of the filter. The filter is obtained by means of modifying the structure based on the basic circuit shown in Fig.7, taking into consideration the various parasitic effects caused by the three-dimensional LTCC structure. The filter consists of the three conductor layers inserted into the middle portion of the LTCC substrate, with the ground planes on the top and bottom layers. The conductor thickness is 8 um. The diameter of via holes is $0.1 \mathrm{~mm}$. The ground planes are connected by the via holes. The via hole between the coupled line adjusts the coupling condition. The dimensions of the bandpass filter are $6.2 \times 2.7 \times 0.366 \mathrm{~mm}^{3}$, and this size could be fabricated into the LTCC substrate for wireless modules. Fig.13 shows the simulated results using a commercial electromagnetic simulator (HFSS Ansys Inc.). The filter has the wide passband and suppresses second and third harmonics. The filter also has an additional attenuation pole at the low-frequency region.

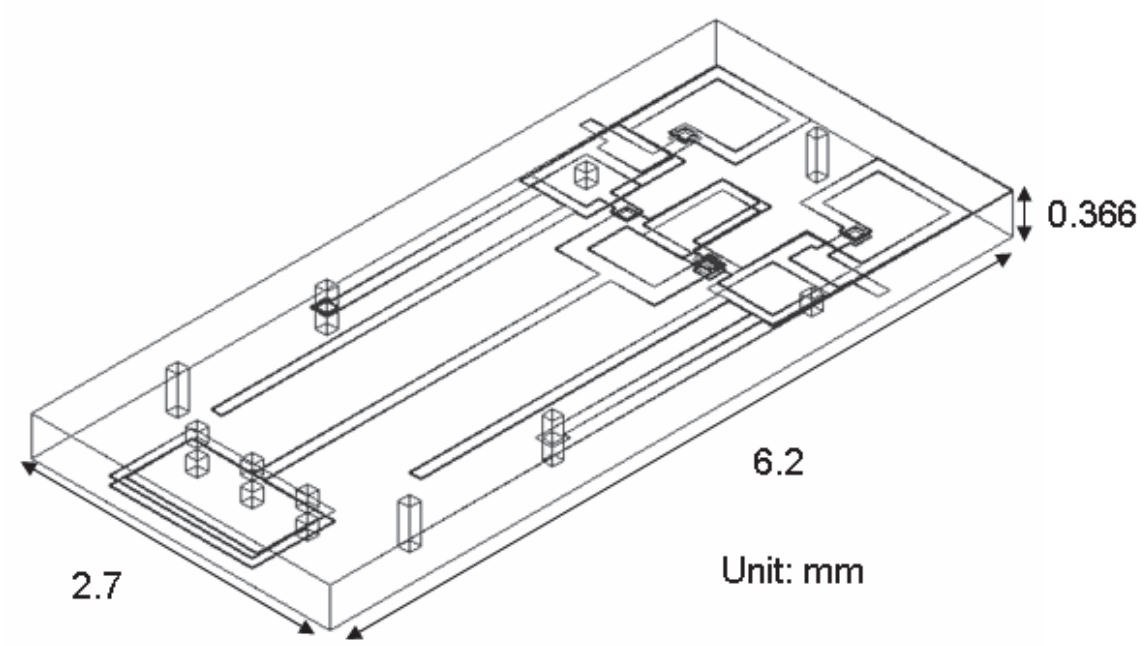

Fig. 10. Three-dimensional structure of the filter.

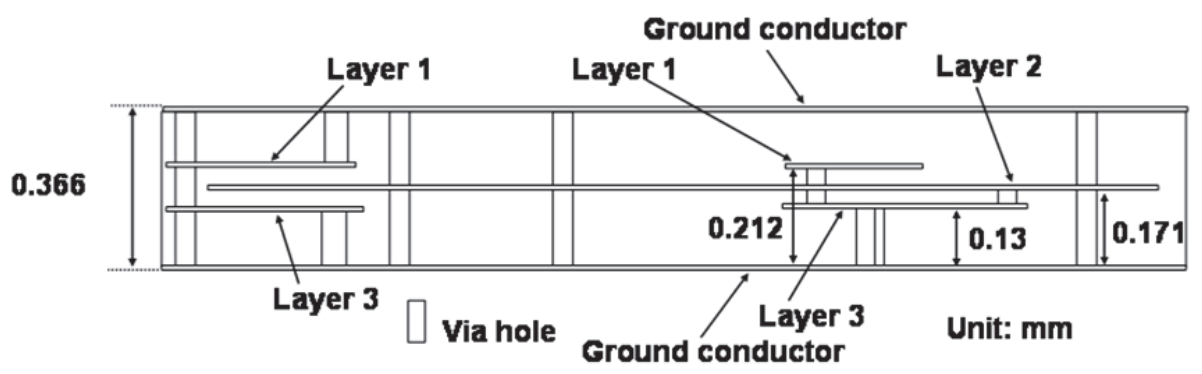

Fig. 11. Cross sectional structure of the filter. 


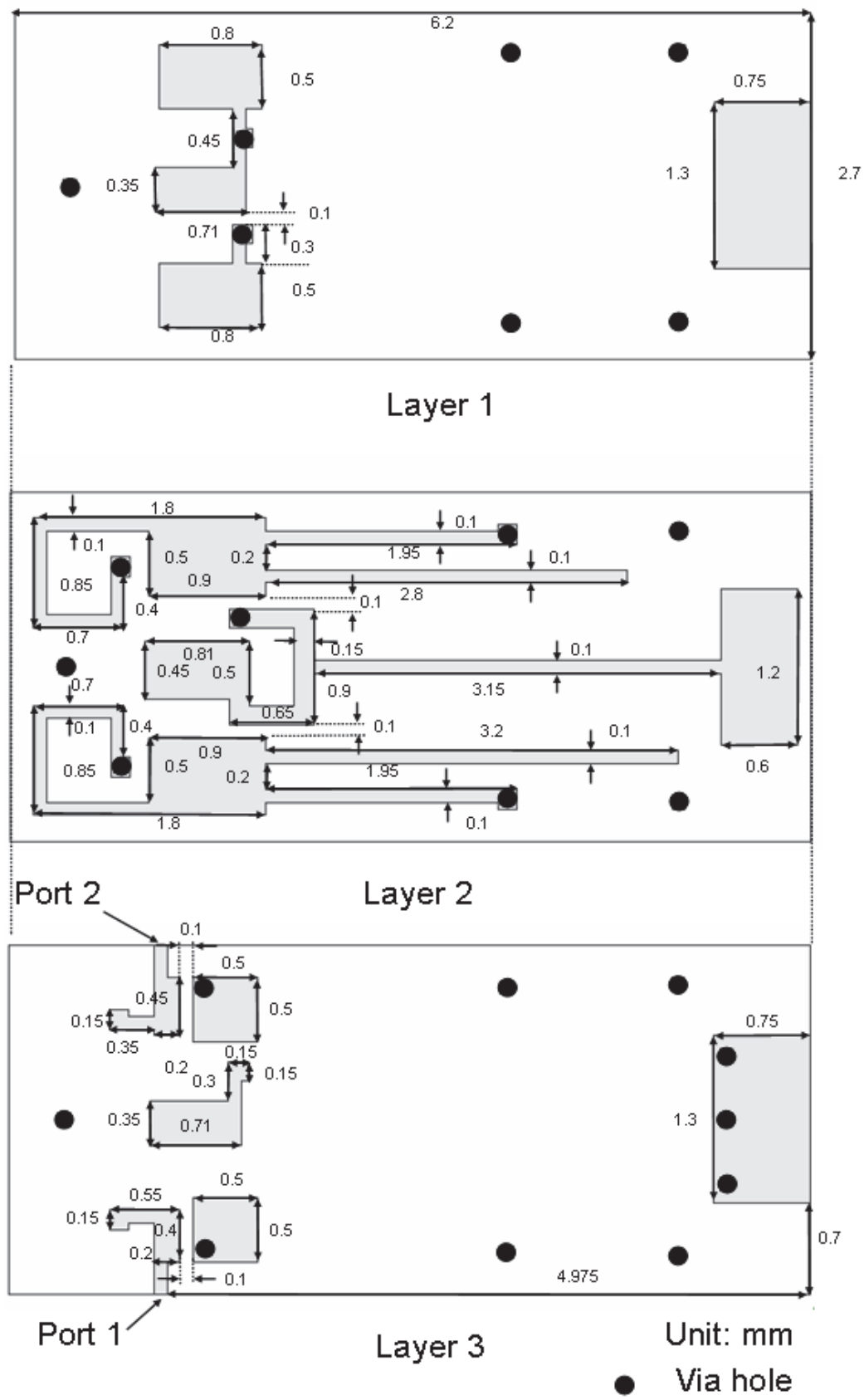

Fig. 12. Top view of the filter. 


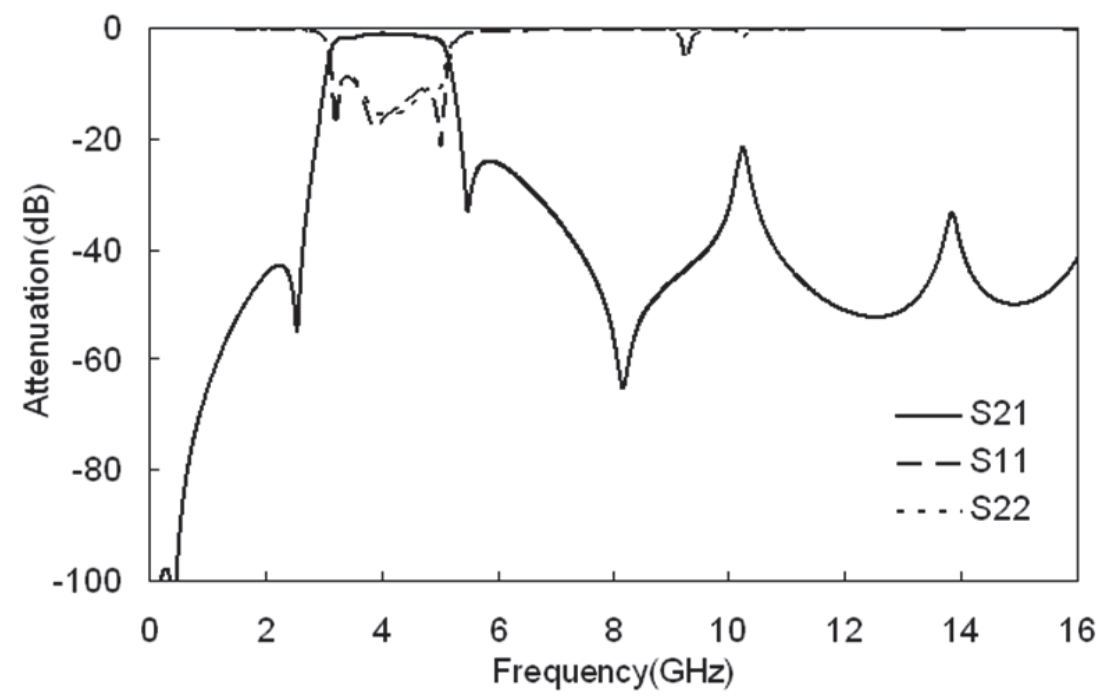

Fig. 13. Simulated results by the electromagnetic simulator.

\section{Experiments}

We verify the effectiveness of the presented method by experiments. Fig. 14 indicates the LTCC structure for the evaluation of the embedded filter. The dimensions of the LTCC

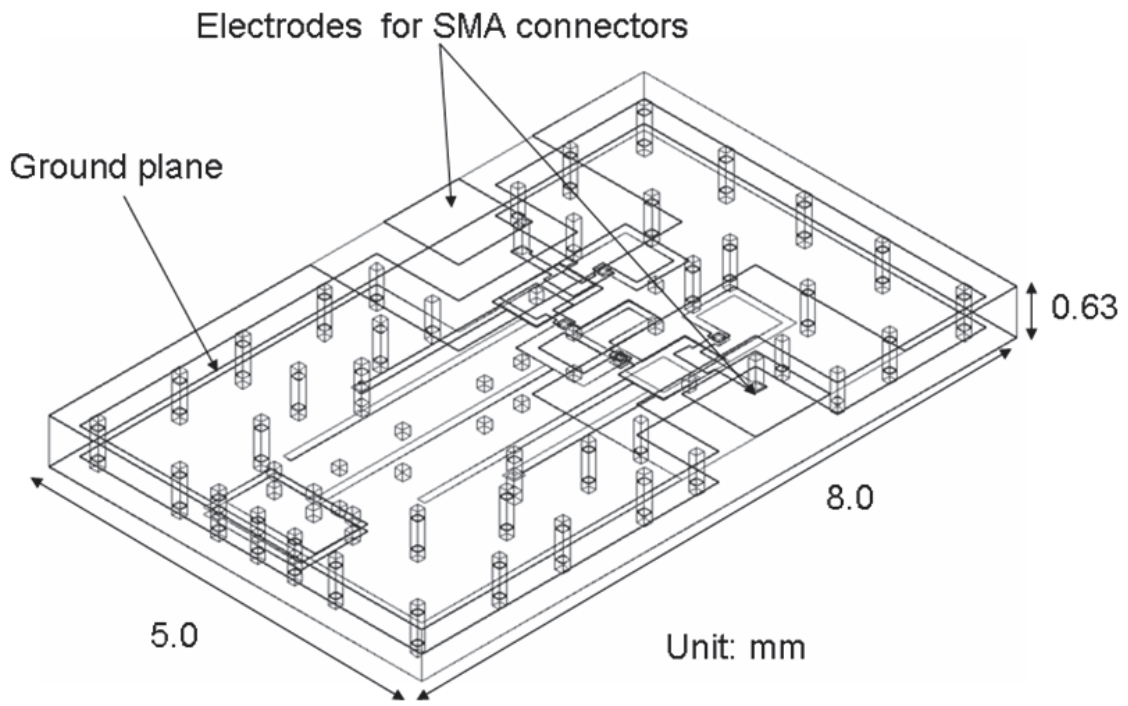

Fig. 14. Structure of the LTCC substrate for evaluation. 
substrate are $8.0 \times 5.0 \times 0.63 \mathrm{~mm}^{3}$. The presented filter $\left(6.2 \times 2.7 \times 0.366 \mathrm{~mm}^{3}\right)$ is fabricated in the substrate. In order to connect the SMA connectors for the evaluation, the top layer of the LTCC substrate has the electrodes for RF signals and a ground plane. The feed lines between the filter and the input/output ports consist of a via hole, a stripline, and the electrode of the top layer. These feed lines are designed $50 \mathrm{ohm}$. Fig. 15 shows a photograph of the LTCC substrate. The prototype which is connected to the SMA connectors is measured by a vector network analyzer (N5230A PNA-L, Agilent Technologies Inc). Fig.16 and Fig.17 indicate the measured results. It is confirmed that the filter suppresses the spurious responses less than $20 \mathrm{~dB}$ up to $16 \mathrm{GHz}$ and has an additional attenuation pole in the low-frequency region. In addition, the insertion loss is less than $3.0 \mathrm{~dB}$ and the group delay is within $1 \mathrm{~ns}$ in the wide passband.

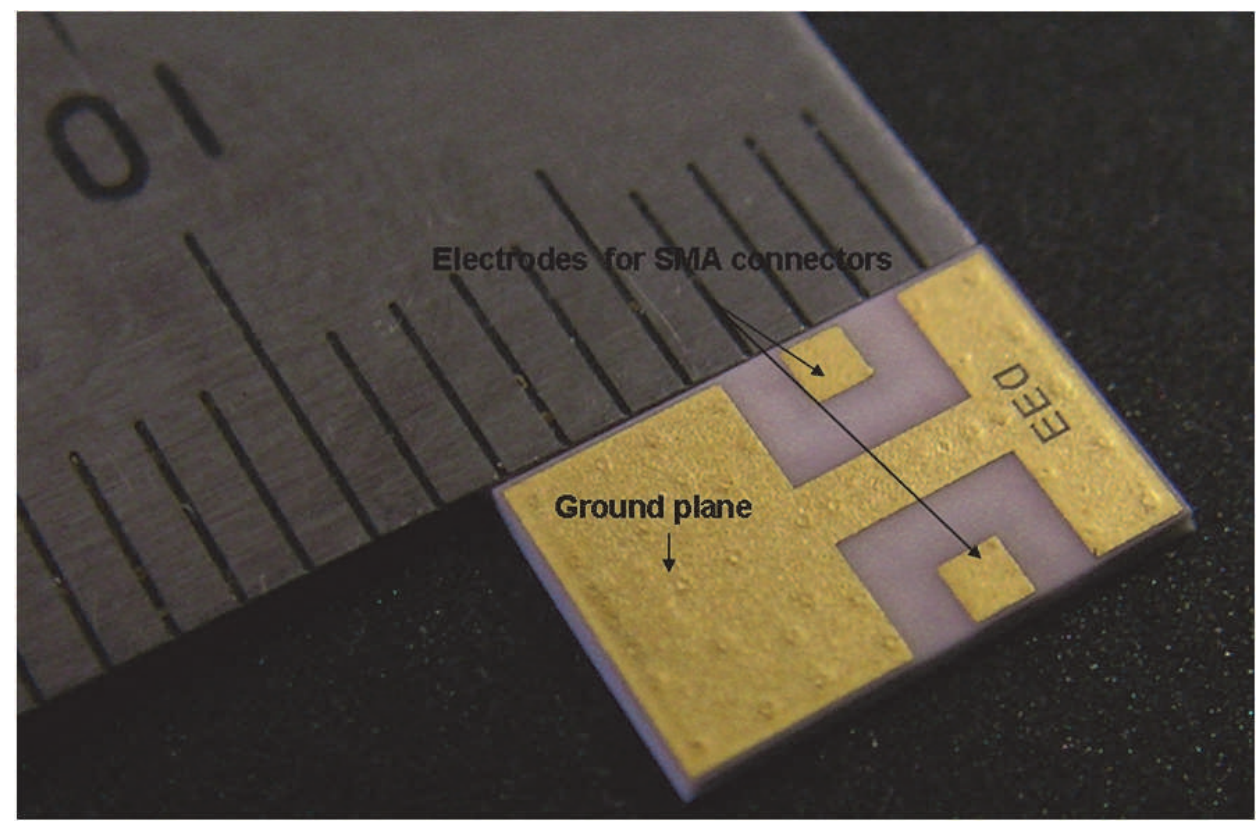

Fig. 15. Photograph of the prototype. 


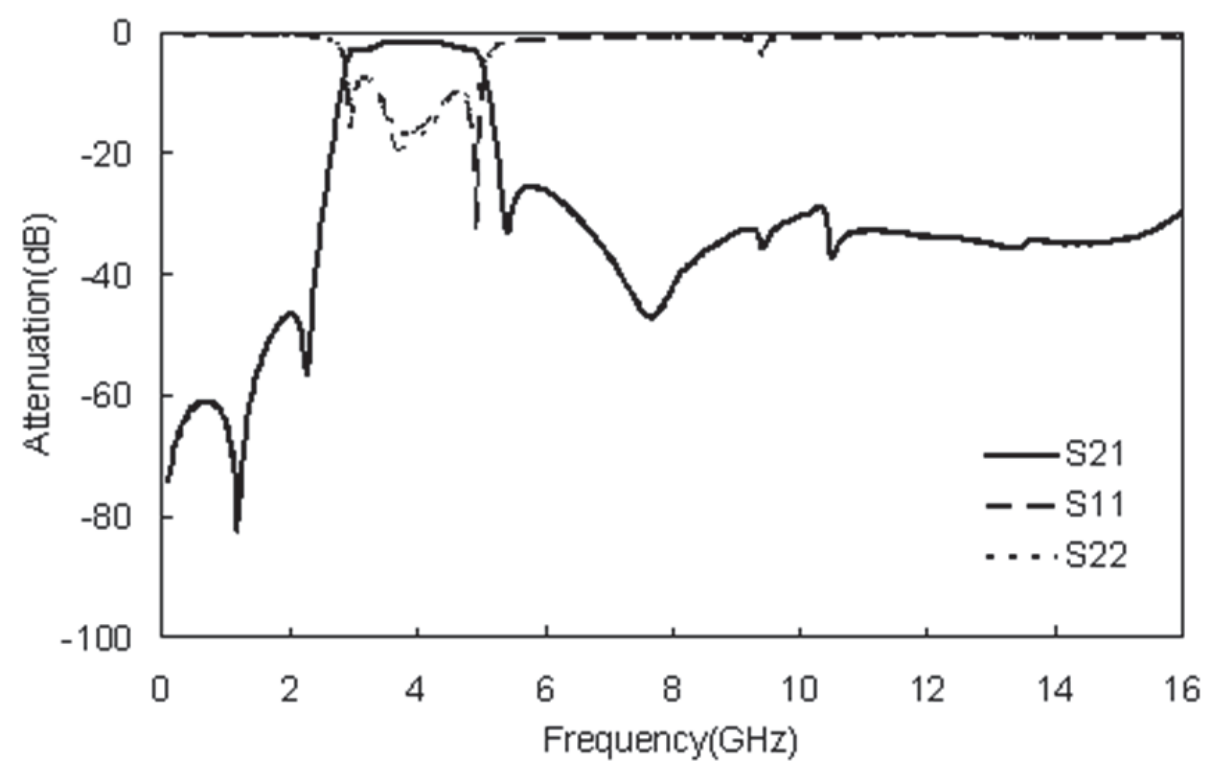

Fig. 16. Measured results of the filter shown in Fig.15.

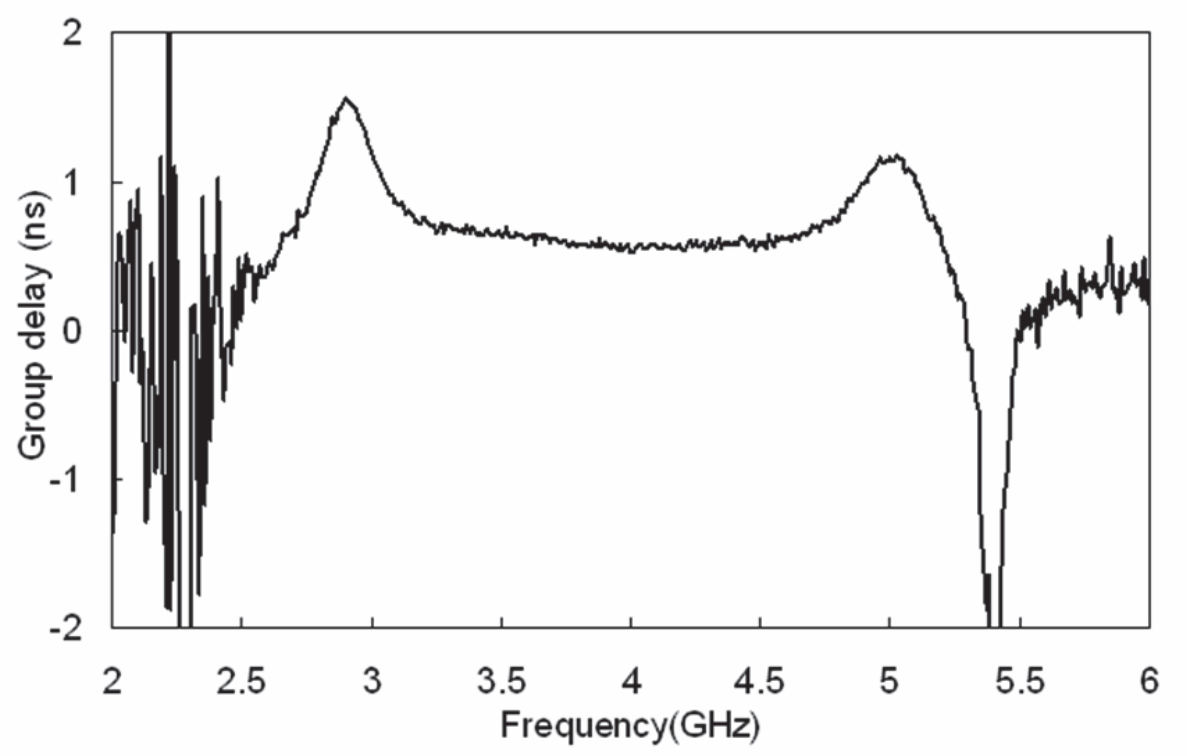

Fig. 17. Measured group delay of the filter shown in Fig.15. 


\section{Conclusion}

In this study, we propose a method for improving out-of-band characteristics for the wideband filter in the LTCC substrate. This method uses the lowpass filters with the coupling structure, which are set at input and output ports of the bandpass filter. This method is very useful for the compact wireless modules because additional compact circuits can suppress spurious responses and can add an attenuation pole in the low-frequency band. The fabricated UWB bandpass filter for the low-frequency band achieves the insertion loss less than $3.0 \mathrm{~dB}$ and the group delay within $1 \mathrm{~ns}$ in the wide passband. The filter also suppresses spurious responses up to $16 \mathrm{GHz}$ and has the good attenuation performances in the low-frequency region.

\section{References}

Lin, Y.-S., Liu, C.-C., Li,K.-M., \& Chen, C.H. (2004). Design of an LTCC tri-band transceiver module for GPRS mobile applications. IEEE Transactions on Microwave Theory and Techniques, Vol. 52, No. 12, pp. 2718-2724.

Wang, G., Van, M., Barlow, F. \& Elshabini, A. (2005). An interdigital bandpass filter embedded in LTCC for 5- GHz wireless LAN applications. IEEE Microwave and Wireless Components Letters, Vol. 15, No. 5, pp. 357-359.

Ishida, H. \& Araki, K. (2004). Design and analysis of UWB bandpass filter with ring filter. IEEE MTT-S International Microwave Symposium, pp. 1307-1310.

Saitou, A., Aoki, H. , Satomi, N., Honjo, K., Sato, K., Koyama, T. \& Watanabe, K.(2005). Ultra-wideband differential mode bandpass filters embeded in self-complementary antennas. IEEE MTT-S International Microwave Symposium, pp. 717-720.

Li, K., Kurita, D. \& Matsui, T. (2005).An ultra-wideband bandpass filter using broadsidecoupled microstrip-coplanar waveguide structure. IEEE MTT-S International Microwave Symposium., pp. 675-678.

Zhu, L., Sun, S. \& Menzel, W.(2005). Ultra-wideband (UWB) bandpass filters using multiplemode resonator. IEEE Microwave and Wireless Components Letters, Vol. 15, No. 11, pp. 796-798.

Horii, Y. , Tanaka, A., Hayashi, T., \& Iida, Y.(2006). A compact multi-layered wideband bandpass filter exhibiting left-handed and right-handed behaviors. IEICE Transactions on Electronics, Vol. E89-C, No. 9, pp. 1348-1350.

Yamamoto, Y., Li, K. \& Hashimoto, O.(2007). Ultra-wideband (UWB) bandpass filter using shunt stub with lumped capacitor. IEICE Electronics Express, Vol. 4, No.7, pp. 227231.

Shaman, H. \& Hong, J.-S.(2007). Input and output cross-coupled wideband bandpass filter. IEEE Transactions on Microwave Theory and Techniques, Vol. 55, No. 12, pp. 2562-2568.

Tanii, K., Shimizu, Y., Nishimura, F., Sasabe, K., Ueno, Y., Wada, K. \& Iwasaki,T.(2008) A study of various wide-band BPFs with attenuation poles using distributed tapcoupling microstrip-line resonators. IEICE Transactions on Electronics (Japanese Edition), Vol.J91-C, No.6, pp.332-340.

Sun, S. \& Zhu, L.(2009). "Multimode-resonator-based bandpass filters. IEEE Microwave magazine, Vol. 10, No. 2, pp. 88-98.

Oshima, S., Wada, K., Murata, R., \& Shimakata, Y. (2008). A study of a compact multilayer wideband bandpass filter in LTCC substrate using distributed resonator with 
attenuation poles consisted of a capacitor and $\lambda / 2$ open-ended stub," IEICE Transactions on Electronics (Japanese Edition), Vol.J91-C, No.8, pp.409-417.

Oshima, S., Wada, K., Murata, R., \& Shimakata, Y.(2010) . Multilayer dual-band bandpass filter in low temperature co-fired ceramic substrate for ultra-wideband applications. IEEE Transactions on Microwave Theory and Techniques, Vol.58, No.3, pp.614-623.

Ghorashi, S.A., Allen,B., Ghavami, M., \& Aghvami, A.H. (2004). An overview of MB-UWB OFDM, IEE Seminar on Ultra Wideband Communications Technologies and System Design, 2004. , pp.107- 110.

Kurita,D.\& Li, K. (2007). Super UWB lowpass filter using open-circuited radial stubs. IEICE Electronics Express, Vol.4, No.7, pp.211-215.

Ohwada, T., Ikematu, H., Oh-hashi, H., Takagi, T. \& Ishida, O.,(2002). A Ku-band low-loss stripline low-pass filter for LTCC modules with low-impedance lines to obtain plural transmission zeros. IEEE MTT-S International Microwave Symposium, pp. 1617-1620. 


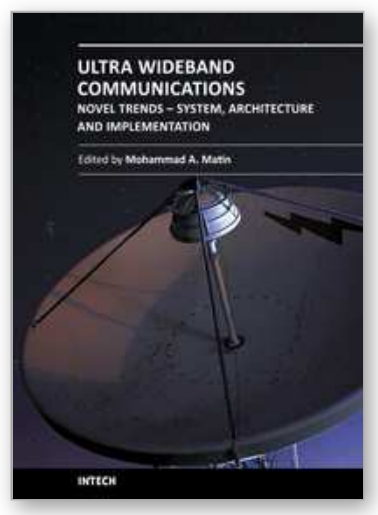

\author{
Ultra Wideband Communications: Novel Trends - System, \\ Architecture and Implementation \\ Edited by Dr. Mohammad Matin
}

ISBN 978-953-307-461-0

Hard cover, 348 pages

Publisher InTech

Published online 27, July, 2011

Published in print edition July, 2011

This book has addressed few challenges to ensure the success of UWB technologies and covers several research areas including UWB low cost transceiver, low noise amplifier (LNA), ADC architectures, UWB filter, and high power UWB amplifiers. It is believed that this book serves as a comprehensive reference for graduate students in UWB technologies.

\title{
How to reference
}

In order to correctly reference this scholarly work, feel free to copy and paste the following:

Shinpei Oshima, Kouji Wada, Ryuji Murata and Yukihiro Shimakata (2011). Method for Improving Out-ofBand Characteristics of a Wideband Bandpass Filter in an LTCC Substrate, Ultra Wideband Communications: Novel Trends - System, Architecture and Implementation, Dr. Mohammad Matin (Ed.), ISBN: 978-953-307461-0, InTech, Available from: http://www.intechopen.com/books/ultra-wideband-communications-noveltrends-system-architecture-and-implementation/-method-for-improving-out-of-band-characteristics-of-awideband-bandpass-filter-in-an-ltcc-substrate

\section{INTECH}

open science | open minds

\section{InTech Europe}

University Campus STeP Ri

Slavka Krautzeka 83/A

51000 Rijeka, Croatia

Phone: +385 (51) 770447

Fax: +385 (51) 686166

www.intechopen.com

\section{InTech China}

Unit 405, Office Block, Hotel Equatorial Shanghai

No.65, Yan An Road (West), Shanghai, 200040, China

中国上海市延安西路65号上海国际贵都大饭店办公楼 405 单元

Phone: +86-21-62489820

Fax: +86-21-62489821 
(C) 2011 The Author(s). Licensee IntechOpen. This chapter is distributed under the terms of the Creative Commons Attribution-NonCommercialShareAlike-3.0 License, which permits use, distribution and reproduction for non-commercial purposes, provided the original is properly cited and derivative works building on this content are distributed under the same license. 